\title{
O ESTEREÓTIPO E AS DIVERSIDADES
}

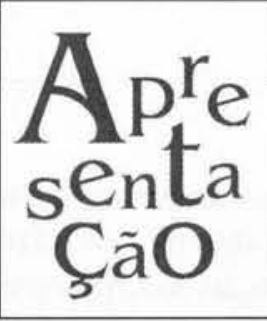

discussão sobre possibilidades de uma educação cuja natureza seja o res$A$ peito à diversidade sociocultural, garantindo, desse modo, o convívio cons1 trutivo na diferença, através do diálogo e do respeito mútuo, tem sido priorizada em vários segmentos.

Nesse campo, consideramos que focar a questão do estereótipo permite tratar dessa temática de modo abrangente pois, através de sua conceituação, poderemos mostrar que a carga negativa de preconceitos e pré-juízos que ele em geral carrega, condicionando comportamentos de repúdio ao outro, é passada muitas vezes de geração a geração, até mesmo sem que nos demos conta disso.

Por outro lado, permite também que a reflexão perpasse vários campos: a questão das etnias, a intolerância frente às desigualdades sociais, a padronização de linguagens e de comportamentos e, nessa fase de globalização, a problemática das relações Norte-Sul, entre muitos outros.

Possibilita, ainda, uma outra leitura dos meios de comunicação: até que ponto é a utilização de estereótipos que facilita a presença dos meios de comunicação em nosso cotidiano, operando no sentido da manutenção dessa visão cristalizada e influenciando-nos?

\section{APROXIMAÇÕES AO CONCEITO}

A faculdade de aprender a falar é característica de qualquer ser humano, porém a fala, manifestação concreta da língua, só se desenvolve no processo social de educação, no bojo de uma cultura, constituindo-se como base do pensamento conceptual. Há, portanto, uma unidade linguagem-pensamento. Quando o homem aprende a falar, ele aprende também a pensar, ou seja, passa a relacionar-se com o mundo através predominantemente de palavras, as quais transportam conceitos e estereótipos.

Não se pode fazer uma distinção precisa entre conceito e estereótipo, a não ser apontando para o fato de que a descrição da realidade, que se obtém através de um processo cognitivo com uma tendência majoritária (não unicamente) objetivo-descritiva, resulta do/no

\section{A AUTORA}

\section{Maria Aparecida Baccega}

Professora Livre-Docente do Departamento de Comunicações e Artes da ECA-USP. Diretora Editorial da Revista Comunicação \& Educação. 
conceito, ao passo que no estereótipo encontraremos a predominância dos aspectos valorativos, dos juízos de valor, com suas bases emocionais.

Segundo Lippmann, quando nos aproximamos da realidade, "não vemos primeiro para depois definir, mas primeiro definimos e depois vemos"'. Aí está o estereótipo: são "os tipos aceitos, os padrões correntes, as versões padronizadas". Eles interferem na nossa percepção da realidade, levando-nos a "ver" de um modo pré-construído pela cultura e transmitido pela linguagem.

Escrito por um jornalista nas primeiras décadas deste século, esse texto pode ser considerado o discurso fundador das reflexões contemporâneas sobre o tema. Segundo ele, "o primeiro lugar em que se deve buscar explicação (para os estereótipos) é o quarto das crianças, a escola e a igreja"2.

Também Eclea Bosi ${ }^{3}$ considera que, quando procuramos conhecer a realidade, ocorre "um processo de facilitação e de inércia. Isto é, colhem-se aspectos do real já recortados e confeccionados pela cultura. O processo de estereotipia se apodera da nossa vida mental".

É o que vemos na sociedade contemporânea. Esse "processo de facilitação", em que a escolha, a leitura, a interpretação do indivíduo/sujeito se dá, prioritariamente, a partir de dados previamente recortados e aceitos pela cultura, tem resultado em simplificações excessivas da complexidade dos fatos e acontecimentos sociais. Esse caminho nos permite pensar sobre uma das causas do êxito dos meios de comunicação.

Mas, lembra Eclea Bosi, "quando as condições o permitem, as impressões iniciais são corrigidas e tornam-se mais inteligíveis à luz de novas experiências"4, ou seja, a interação do homem com a realidade, dinâmica, possibilita a todos condições de ultrapassar a barreira do estereótipo.

Quando se fala em estereótipo, é preciso ter clara a distinção entre conformidade e conformismo, pois o estereótipo tem uma multiplicidade de faces. Na verdade, o indivíduo acaba por orientar-se através de estereótipos e de normas, conformando-se ao seu grupo, buscando garantir o êxito de suas ações e a aceitação social. Até porque, sem essas normas e estereótipos, estaríamos sempre redescobrindo a América e constatando de novo que o fogo queima e pode matar. Isso é o que leva Lippmann a afirmar que há "economia" no estereótipo, que ele pode agilizar a percepção. Aqui temos a conformidade. Há que se estar atento, porém, para o fato de que essa conformidade que, no limite, faz parte da natureza do viver em sociedade, pode converter-se em conformismo, quando não são oferecidas ao indivíduo/sujeito possibilidades reais de inserção na sua sociedade, numa interação em que ele seja efetivamente sujeito, em que ele tenha voz e sua voz seja respeitada. (E aqui a escola desempenha papel fundamental.) Nesse caso, os procedimentos e atitudes da vida cotidiana, que se regem pela conformidade com o estabeleci-

1. LIPPMANN, Walter. Estereótipos. In: STEINBERG, Charles S. (org.). Meios de comunicação de massa. Trad. Otávio Mendes Cajado. São Paulo: Cultrix, 1972. p.151.

2. LIPPMANN, Walter. Estereótipos. op. cit. p.159.

3. BOSI, Eclea. A opinião e o estereótipo. Contexto. São Paulo: Hucitec, n.2. mar. 1977. p.98.

4. BOSI, Eclea. A opinião e o esteré́tipo. op. cit. p.99. 
do, acabam por penetrar em outras esferas da sociedade: o indivíduo/sujeito "vê" o que deixaram pronto para ele através da inculcação de estereótipos, passando a ser apenas a "voz do dono", deixando de lado sua condição de "dono da voz".

\section{DO ESTRANHAMENTO AO ESTEREÓTIPO}

Cada um de nós vive num determinado país, numa região desse país, pertence a uma classe social, nasceu numa família. E circulamos nesse universo, onde trabalhamos, amamos, construímos, aceitamos e rejeitamos. Mesmo dentro desse universo só podemos participar diretamente de poucos fatos e acontecimentos: ou porque somos protagonistas ou antagonistas diretos, ou porque somos espectadores, sempre ativos, ou seja, interpretando-os de acordo com nossa cultura.

Tomamos conhecimento dos outros fatos que ocorrem no nosso pequeno universo ou dos que ocorrem fora dele - e na ampliação desse universo os meios de comunicação exercem um importante papel - através de relatos. Todo relato vem impregnado dos valores e estereótipos da cultura de quem relata. Na maioria das vezes os relatos que chegam até nós são o resultado das versões de vários sujeitos, às quais cada um aportou com seus condicionamentos. Esses relatos nos são comunicados ou no boca-a-boca, ou através das mais sofisticadas tecnologias usadas pelos meios de comunicação.

Mesmo quando observamos diretamente o fato, ou dele participamos, vamos "vivê-lo", ou depois relatá-lo, de acordo com nosso ponto de vista, que é formado predominantemente pela linguagem, sobretudo pela palavra, que, como vimos, transporta os conceitos e os estereótipos. Desse modo, acabamos por dividir os fatos em dois grandes blocos: aqueles considerados "normais" em nossa cultura, ou aqueles considerados "estranhos".

Robert Lado ${ }^{5}$ nos dá um exemplo bastante esclarecedor: trata-se da tourada. Em sua forma, ela apresenta um homem, com capa vermelha e espada, que desafia e mata um touro. Conseguimos perceber, sem problemas, o toureiro, o touro, a música, a vestimenta etc. A distribuição da apresentação dos espetáculos também não constitui problema: preferem-se determinados dias da semana e determinadas horas do dia. Já a percepção do sentido é muito complexa. Para o espanhol a tourada é um esporte, uma demonstração de bravura, uma arte, onde se destaca a primazia do homem sobre o animal. Já em outras culturas, entre as quais a brasileira, a tourada é cruel, pois o touro sempre deve morrer; é perigosa, pois o toureiro também pode morrer ou ferir-se gravemente. E ficamos nos perguntando como as pessoas podem apreciar esse espetáculo.

No Brasil, entretanto, em algumas camadas da população, ainda existe a briga de galos e isso, entre os envolvidos, é considerado "normal". Ou ainda a célebre farra do boi, realizada em Santa Catarina.

Um outro exemplo que nos parece muito saboroso: no Brasil, é comum as pessoas afirmarem que todos os orientais - japoneses, coreanos, chineses, vietnamitas

5. LADO, Robert. Introdução à lingüística aplicada. Petrópolis: Vozes, 1971. 
etc. - são iguais. Quando se completaram 70 anos de imigração japonesa no Brasil, os meios de comunicação dedicaram espaço ao assunto. Um repórter do Jornal da Tarde, Marcos Faermann, entrevistou uma senhora japonesa que havia chegado ao Brasil no primeiro navio de imigrantes. Perguntou-lhe o que mais a espantara ao chegar. E sua resposta foi precisa: o fato de que todas as pessoas eram iguais.

Que significam esses exemplos? Que quando não conhecemos alguma coisa que se coloca em nosso mundo já estruturado, nós a vemos como um borrão, uma mancha, a qual preenchemos com nossos significados. Procuramos distinguir os elementos de que ela se compõe, ou seja, recortamos e damos significado às partes, de acordo com a visão de mundo que carregamos. Assim é que os brasileiros eram "estranhos" para os japoneses, e os japoneses eram "estranhos" para os brasileiros, construindo-se, desse modo, em cada um desses pólos, uma visão muitas vezes distorcida do outro, que era apenas o diferente.

\section{A DISSIMULAÇÃO DO ESTEREÓTIPO}

Vivemos num mundo que nos chega editado pelos meios de comunicação, que nos contam a "realidade" através de relatos impregnados de estereótipos que no mais das vezes nos são desfavoráveis. São esses os relatos que recebemos cotidianamente e que vão preencher nossa visão de mundo não apenas sobre os fatos de que não participamos, mas, muitas vezes, também sobre os fatos do universo em que vivemos.

O estereótipo, assim como o conceito, é um reflexo/refração específica da realidade - ou seja, reflete com desvios, como um lápis que, colocado em um copo de água, "entorta" -, mas o estereótipo comporta uma carga adicional do fator subjetivo, que se manifesta sob a forma de elementos emocionais, valorativos e volitivos, que vão influenciar o comportamento humano. Ele se manifesta, portanto, em bases emocionais, trazendo em si, como já dissemos, juízos de valor preconcebidos, preconceitos, e atuam na nossa vontade. Nossa cultura está plena de exemplos, entre os quais podemos lembrar os indígenas e os afro-descendentes. "Historicamente, no Brasil, tentou-se justificar, por essa via (a dos argumentos de ordem racial/étnica), injustiças cometidas contra povos indígenas, contra africanos e seus descendentes, da barbárie da escravidão às formas contemporâneas de discriminação e exclusão, desses e de outros grupos étnicos e culturais, em diferentes graus e formas". ${ }^{6}$ Quem transporta tais discriminações é o estereótipo, uma das manifestações do signo lingüístico, da palavra.

Grave é que o estereótipo é usado como se fosse apenas um conceito, e a carga negativa que carrega fica dissimulada. Apreendido concomitantemente à aprendizagem da língua materna, consideramos absolutamente necessário que se estabeleça nas escolas um processo continuado de reflexão sobre os estereótipos de

6. BRASIL. Secretaria de Educação Fundamental. Parâmetros curriculares nacionais: pluralidade cultural, orientação sexual / Secretaria de Educação Fundamental. Brasília: MEC/SEF, 1997. p.45. 
nossa cultura, tornando claro a cada momento que temos que distingui-los dos conceitos, que eles não são conceitos.

Esse é, entre muitos outros, um dos caminhos para se concretizar um processo educativo que, aberto ao diálogo com o outro, com o diferente, preserve identidades, formando cidadãos.

Este número da revista traz contribuições para ampliar essa discussão.

\section{ARTIGOS NACIONAIS}

Solange Martins Couceiro de Lima discute o conceito e as práticas do multiculturalismo no seu artigo Multiculturalismo, alertando para os perigos do chamado "mito da democracia racial", que sempre vigiu entre nós. Para a autora, é preciso que o multiculturalismo signifique "o reconhecimento da contribuição, do valor, dos direitos, da igualdade de oportunidades de todos os grupos étnicos e culturais". Para que isso venha a ocorrer, é preciso acabar com os estereótipos que maculam o sentido da contribuição de cada uma das minorias, justificando essa sociedade de desiguais em que temos vivido.

Desafios comunicacionais no Mercosul traz a contribuição de José Marques de Melo para as discussões sobre multiculturalismo e comunicação, apontando as diversidades culturais e a construção de identidades que dela resultam no âmbito do processo de globalização. $\mathrm{O}$ autor chama a atenção para as iniciativas no campo da cultura e da comunicação, as quais não têm merecido, no âmbito do Mercosul, o mesmo destaque das articulações de natureza econômica.

Quando tratamos de violência, ao invés de negá-la, considerando-a tão-somente como uma parte maldita da sociedade, "deveríamos procurar compreender como ela se inscreve nas relações sociais e no nosso imaginário", diz Theophilos Rifiotis, em seu artigo Dilemas éticos no campo da violência. Em outras palavras: importante compreender a violência sem os estereótipos que compõem seu campo, entre os quais podemos citar: ela se daria na periferia, seria praticada por determinadas camadas da sociedade e não por outras etc. Enfim, a realidade não tem a simplificação que os estereótipos nos passam.

Comunicação dirigida nas escolas, de Waldir Ferreira, trata dos diferentes instrumentos a que a escola pode recorrer para aperfeiçoar a comunicação com seu público-alvo. Neste sentido, é importante salientar que, para impedir o ruído na comunicação, além da adequada utilização de tais recursos, é salutar perceber a comunicação como processo social, no qual a cultura e a história têm papéis relevantes.

\section{ARTIGOS INTERNACIONAIS}

Na segunda e última parte do artigo de Robert White, Tendências dos Estudos de Recepção, temos diferentes abordagens teóricas e metodológicas sobre a linha de pesquisa da Recepção. As perspectivas analisadas destacam o meio 
social, a cultura e as múltiplas inter-relações entre emissores / receptores dos meios de comunicação como fatores preponderantes na análise do processo comunicacional. Nesta arena, a disputa pelos sentidos passa pela capacidade de localizar e questionar os estereótipos, desnudando os significados tácitos e muitas vezes apreendidos como sinônimo de verdade.

$\mathrm{O}$ teatro enquanto arte por excelência é um grande demolidor de estereótipos, devido à multiplicidade e amplitude de olhares que proporciona. Mafra Gagliardi, autora de $O$ teatro, a escola e o jovem espectador, salienta que "diferentemente do que ocorre na televisão, no cinema ou nas histórias em quadrinhos (....), no teatro a cena se oferece ao olhar em sua totalidade e complexidade, é o olho que deve escolher seu ponto de vista e seu percurso".

\section{ENTREVISTA}

Maria Thereza Fraga Rocco, em entrevista a Roseli Fígaro, Escola, meios de comunicação e a relação professor-aluno, destaca o papel do educador e as muitas possibilidades de uso e exploração dos meios de comunicação como fatores fundamentais na melhoria da qualidade de ensino no Brasil. Discute o abandono em que se encontra a escola pública e o faz mostrando-a como espaço de sofrimento que não dialoga nem com estudantes nem com professores. Resgatar a escola pública significa vê-la como espaço de produção de conhecimento e cultura.

\section{CRÍTICA}

Em Telenovela: arte do cotidiano, Maria Lourdes Motter comenta como a telenovela brasileira, ao construir um estilo próprio, através da interface ficção/realidade, faz uma crônica do cotidiano da vida brasileira. Os estereótipos são o ponto central da análise da autora que vai demonstrando como a realidade, editada nos jornais, revistas e telejornais, pauta as tramas desenvolvidas pelas telenovelas. Assim como elas, as telenovelas, ao tratarem de aspectos polêmicos do cotidiano, tais como homossexualismo, desaparecimento de crianças, racismo, reivindicações sociais e movimentos de trabalhadores, acaba criando laços de identidade, fazendo com que os telespectadores discutam tais problemas e formem uma opinião.

\section{DEPOIMENTO}

Nada mais importante na atualidade para quebrar estereótipos do que uma imprensa independente, criativa e que trate os temas da atualidade com profundidade e visão ampla. É o que vemos no relato do jornalista e editor da revista Caros Amigos, Sérgio de Souza. Profissional de inquestionável competência, esteve à frente de uma das publicações mais importantes da imprensa brasileira, a revista Realidade. Em Caros Amigos, a irreverência e o compromisso com a abordagem 
aprofundada do fato representa uma luz que permite ver o quanto o mercado está abarrotado do fast-food impresso.

\section{EXPERIÊNCIA}

Prazer é a chave de leitura desta seção de Comunicação \& Educação. O prazer de degustar o aprendizado, de tirar da experimentação do paladar, do sonho, do trabalho, o resultado do saber. Aulas de culinária para crianças, de Theodora M. Mendes de Almeida, conta a prática pedagógica de uma escola preocupada em desfazer estereótipos e introduzir os alunos no mundo da Ciência. Ler e escrever, recontar, recriar são possibilidades prazerosas e de profundo significado quando exercitadas com método e profissionalismo. É a experiência contada em Descobrir o prazer de escrever, da professora Maria Júlia Rangel De Boni. Ambos são relatos de trabalhos pedagógicos profundamente comprometidos com o exercício da cidadania.

\section{POESIA}

Os cem anos de Federico García Lorca, poeta e dramaturgo catalão que colocou seu trabalho a favor da liberdade e da revolução, convida-nos a refletir sobre o alumbramento, a inspiração, o maravilhamento que todos temos que ter para com a vida, o homem e as coisas do mundo. Tengo miedo a perder la maravilla tem tradução de Renata Pallottini.

\section{SERVIÇOS}

Cultivar a cultura brasileira tem sido um dos objetivos do Instituto Moreira Salles, como Jandira Queiroz demonstra em seu artigo Instituto Moreira Salles. A disponibilidade desses acervos ao público, principalmente aos estudantes, pode ser uma grande experiência e serviço prestado à comunidade. Vale a pena conferir.

\section{BOLETIM BIBLIOGRÁFICO}

Em Videografia, Maria Ignês Carlos Magno costura História, poesia e cinema enquanto potencialidades de leituras para transformações, revoluções pessoais e sociais. A poesia dialoga com a realidade, permitindo ver a história em sua complexidade. Ismar de Oliveira Soares destaca títulos importantes em Bibliografia sobre Comunicação e Educação e Anamaria Fadul chama a atenção para artigos, dissertações e teses relevantes em Bibliografia sobre telenovela brasileira. 
Resumo: A conceituaçāo de estereótipo, proposta pela autora, destaca o seu significado como preconceito, pré-juízo, na maioria das vezes, incorporado como senso comum e passado de geração a geração. No estereótipo predominam aspectos valorativos, juízos de valor, com bases emocionais. A autora ressalta a importância de se diferenciar, quando se fala em estereótipo, os aspectos de conformidade e de conformismo. Chama a atençāo para a dissimulaçāo da carga negativa do estereótipo, utilizado, muitas vezes, apenas como conceito. Esse aspecto é bastante explorado principalmente pelos meios de comunicação. Mostra a importância do conhecimento dos estereótipos como uma das bases para o diálogo entre as diversidades socioculturais.

Palavras-chave: estereótipo, cultura, linguagem, conceito, diversidades socioculturais
Abstract: The concept of stereotype, proposed by the author, emphasizes its meaning as prejudice, pre-concept, in most cases, built in as a common sense and passed over from generation to generation. Value aspects and judgements prevail in the stereotype, on an emotional basis. When speaking of stereotypes, the author highlights the importance of differentiating agreement and conformity aspects. She calls attention for the dissimulation of the stereotype negative side, used, most times, only as a concept. This aspect is fairly exploited, specially by the means of communication. She shows the importance of knowing the stereotypes as one of the basis for a dialogue among socialcultural diversities.

Key words: Stereotype, culture, language, concept, social-cultural diversity 